\title{
Stable isotopic records in unionid shells \\ as a paleoenvironmental tool
}

\section{S. Verdegaal, S.R. Troelstra ${ }^{*}$, C.J. Beets \& H.B. Vonhof}

Faculty of Earth and Life Sciences, Vrije Universiteit, de Boelelaan 1085, 1081 HV Amsterdam, the Netherlands.

* Corresponding author. Email: simon.troelstra@falw.vu.nl

Manuscript received: April 2005; accepted: August 2005

\section{Abstract}

Stable oxygen and carbon isotope studies were performed on unionid shells from Rhine and Meuse rivers. Results show that the characteristic isotopic signature of each river is well documented in the shells with average $\delta^{18} 0$ values of $\sim 9.00 \%$ for the Rhine specimens and of $6.5 \%$ for the Meuse unionid. The average $\delta^{18} 0$ values of the shell material corresponds to the average $\delta^{18} 0$ of the to rivers and thus identifies Rhine or Meuse sedimentary sequences. All $\delta^{18} 0$ records show distinct seasonality, which may be used to reconstruct past riverconditions

Keywords: stable isotopes, unionids, isotopic signature, paleo-reconstructions

\section{Introduction}

The Rhine and Meuse are the two most important rivers in the Netherlands that transport melt- and rainwater to the sea. Together they have a drainage area that includes the Ardennes, NW-France and SW-Germany and extends to the Swiss Alps (Fig. 1). During the Quaternary this river-system was modified repeatedly through the interplay of neotectonic movements, sealevel rise and human interference (Berendsen \& Stouthamer, 2001). Understanding river changes in the past is a prerequisite for predicting future behaviour; however, questions on past flooding frequencies, runoff and seasonality are still largely unanswered. To this means we investigated the potential of shells of the freshwater mollusc Unio crassus nanus as paleoenvironmental archives.

Molluscan carbonates have been studied for their paleoecological, -climatological and -environmental potential (e.g. Klein et al., 1996; Stecher, 1996). Molluscs are relatively longliving (decadal to centennial) and their shells are composed of incrementally secreted growth lines, providing an excellent carbonate archive. Most work is done on marine species but also limited research on freshwater molluscs has been carried

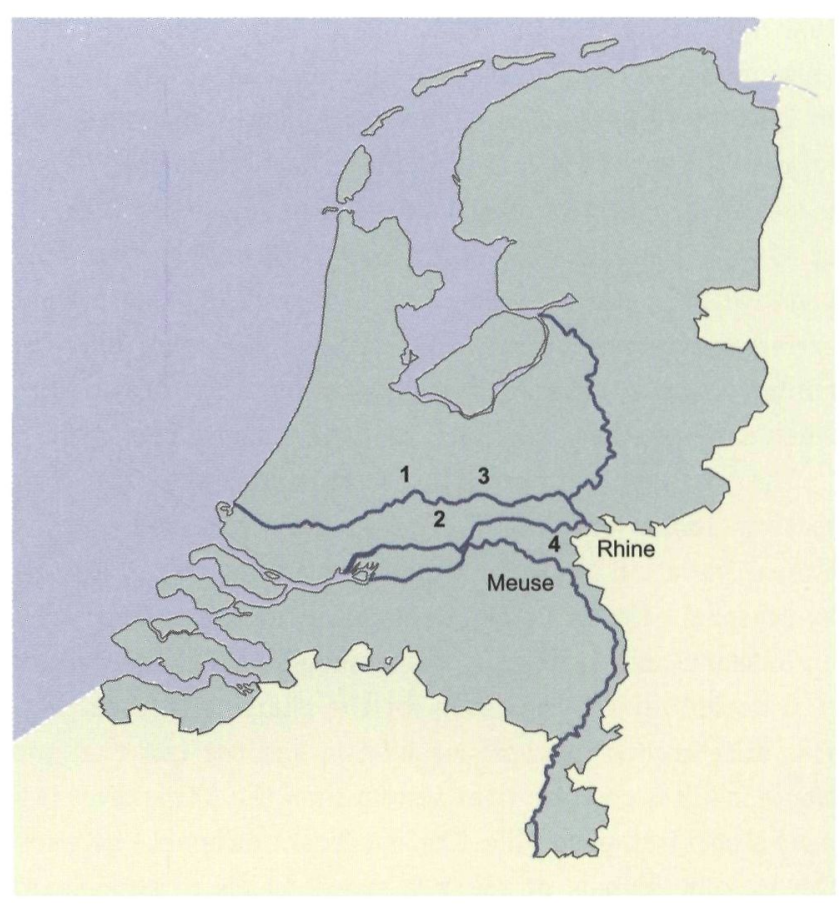

Fig. 1. Rhine and Meuse catchment areas showing sample locations Montfoort (1), Vianen (2), Wijk bij Duurstede (3) en Bergen (4). 
out (Fritz \& Poplawski,1974; Rosenthal \& Katz, 1989; Fastovsky et al., 1993; Dettman, 1999). So far little attention has been paid to the use of freshwater bivalve shells as indicators of past river processes.

Both Rhine and Meuse rivers display a distinct a seasonal signal in their stable oxygen isotope record, but average values and timing of the $\delta^{18} 0$ maxima/minima differ significantly (Mook, 1999). The Rhine water has an average isotopic ratio of $\sim-9 \%$ with maxima during winter, whereas the Meuse water reaches its peak value for $\delta^{18} 0$ during summer and has an average $\mathrm{d} 180$ of $\sim-7 \%$. The difference in average value is caused by a different source-input: meltwater from the Swiss Alps and subsidiary rivers in southern Germany for the Rhine, and rainwater from France and the Ardennes for the Meuse. The more negative average $\delta^{18} 0$ value of Rhine water is a result of the geographical position of its source. Mook (1999) states that the ${ }^{18} 0$ content of atmospheric water decreases when transported more inland (continental effect) while values become even more negative when the altitude increases (altitude effect). The variations in the $\delta_{\mathrm{w}}$ profile of the Rhine water are caused by varying contributions of Alpine meltwater (approx. 45\% of total) and non-Alpine rivers (Ricken et al., 2003). The meltwater component, which is maximal during summer, lowers the d180 value of the Rhine water, whereas the non-Alpine river component causes more positive $\delta^{18} 0$ values during summer. The $\delta_{\mathrm{w}}$ values for the Rhine have also been measured by Ricken et al. (2003) at the Cologne station from February 1989 to May 1994. Their data partially overlap with the measurements performed by RIVM/CIO. At the Cologne station the isotopic range for $\delta^{18} 0$ is between $-10.25 \%$ o (summer) and $-8.90 \%$ (winter). There is also some scatter in their results, but the large amount of samples gives a better view on the average signal. The values for the winters of 1990 to 1994 are $-8.9,-9.2,-9.4,-8.9$ and $-8.8 \%$ respectively and for the summers of 1989, 1991 and 1992 a minimum of $-10.25 \%$ is measured. The other two summers have average $\delta^{18} 0$ values of $-9.8 \%$. The summers of 1991 and 1992, that have a more negative $\delta^{18} 0$ value compared to 1990 and 1993, also show extreme values in the RIVM/CIO data set. This variability in minimum and maximum $\delta_{\mathrm{W}}$ values must be taken into account when shell- material and water isotopic data are compared.

The $\delta^{18} 0$ profile for the Meuse is far more stable. This river receives rainwater from NE France and the Ardennes. The annual variation in the $d w$ profile of this river is caused by seasonal effects. Higher evaporation during summer $\left({ }^{18} 0\right.$ enrichment) and increasing water supply in fall and winter $\left({ }^{18} 0\right.$ depletion) are the cause for the characteristic pattern. This difference in isotopic mechanism and the fact that the Meuse is a less complex river system than the Rhine gives it a more stable isotopic profile. The significant difference between the isotopic signals of the two rivers makes it possible to distinguish between unionids from Rhine and Meuse.

\section{Materials and methods}

Unionids have been collected at three Rhine locations (dead specimens) and one Meuse locality (collected alive in 1918). The Rhine samples derive from a residual channel belt near Montfoort which was part of the Rhine river system between 3000 and 3500 years ago, from an archeological pit in Wijk bij Duurstede dated at $1200 \mathrm{AD}$ and a loose valve collected in 1992 near Vianen (Fig. 1).

All shells were embedded in epoxy after which thin sections were made over the maximum width of the shells (highest growth rate) in order to sample the growth increments at high resolution. The carbonate part of the shell consists of a prismatic and a nacreous layer, the latter showing tiled growth increments. Because of the relative smaller prismatic layers only the nacreous layers have been used for sampling.

The Merchantek Micromill microsampler technique allows the mollusc preparates to be sampled with a spatial resolution of $70 \mu \mathrm{m}$, corresponding to a resolution of weeks to months dependent on the growth rate. The microsampler consists of a computer-controlled microscope with a stepper-motor-driven $\mathrm{x}-\mathrm{y}-\mathrm{z}$ micropositioning stage under a stationary rotating drill bit. Computer-guided drilling, based on photo-digitised sample paths, allows sequential sample widths to vary in response to fine-scale features in the material under study. After drilling, the sample powder is removed to sampler analyser cups using a scalpel blade and a fine needle. For a sufficient amount of sample the lines selected have to be about $2 \mathrm{~mm}$ in length, a minimum distance between the lines of $70 \mu \mathrm{m}$ is needed and depth of drilling is approximately $150 \mu \mathrm{m}$.

The stable $\delta^{13} \mathrm{C}$ and $\delta^{18} 0$ isotope ratios of the samples were analyzed on a Finnigan MAT 252 mass spectrometer equipped with an automated carbonate extraction line, a so-called Kiel device. This apparatus measures the isotopes of $\mathrm{CO}_{2}$, which is generated by adding few drops of orthophosphoric acid to the samples at a temperature of $80^{\circ} \mathrm{C}$. Approximately $20-50 \mu \mathrm{g}$ of sample were required per analyses, all data are reported versus V-PDB (Vienna Pee Dee Belemnite). The NBS 19 carbonate standard is routinely monitored during sample runs. NBS 19 long-term reproducibility lies within $0.09 \%$ for $\delta^{18} 0$ and $0.05 \%$ for $\delta^{13} \mathrm{C}$.

\section{Results}

Fig. 2 shows the stable oxygen and carbon isotope profiles of the four unionid specimens. The seasonal signal indicates they are 7 - 8 years old. All specimens show less detail with increased age, meaning that main growth is in the first years of life. This early rapid growth helps the animal to settle and to escape predation. (Gittenberger et al, 1998).

The Rhine specimens from Montfoort and Wijk bij Duurstede have an isotopic range of -11 to $-7 \%$ for $\delta^{18} 0$ and the Vianen specimen between -10 and $-8 \%$. The $\delta^{13} \mathrm{C}$ of all three varies 

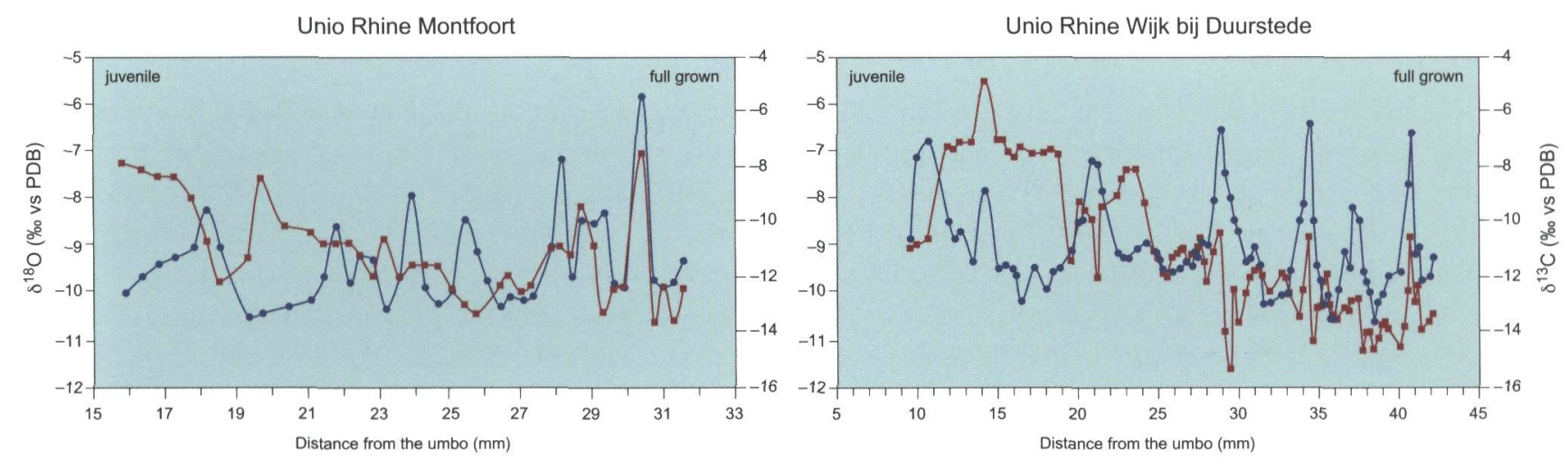

a.
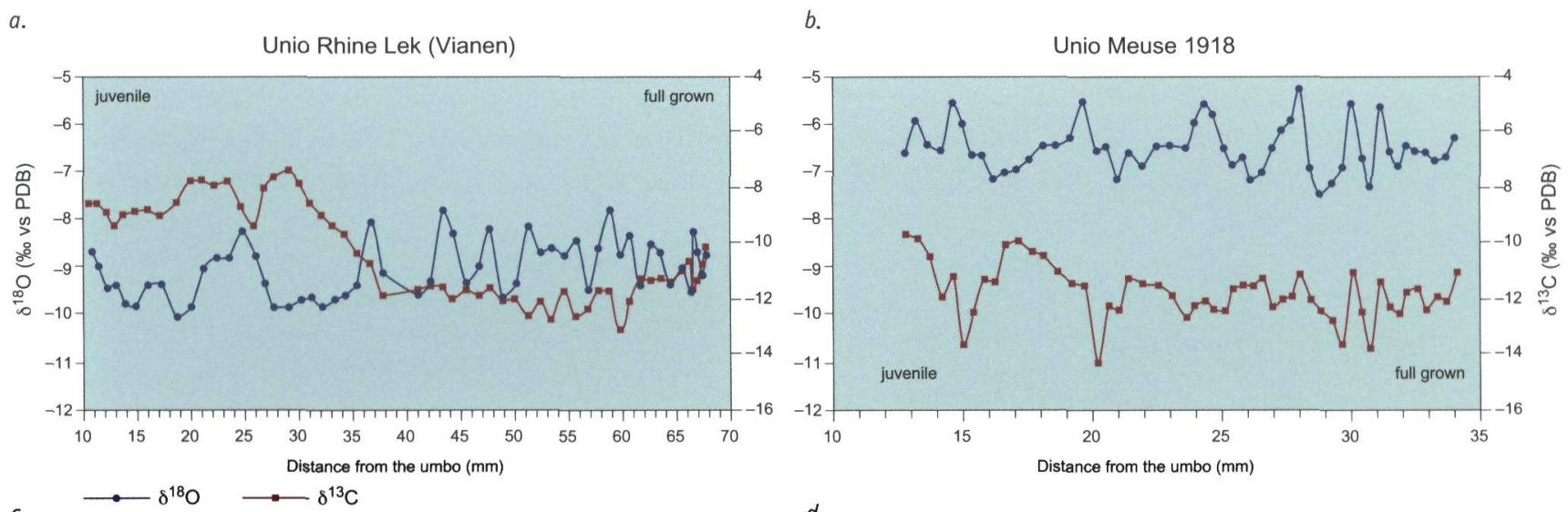

d.

Fig. 2. $\delta^{18} 0$ and $\delta^{13} \mathrm{C}$ for Unio crassus nanus from a. Montfoort (Rhine, from remains of a crevasse); b. Wijk bij Duurstede (Rhine); c. Vianen (Lek); and $d$. Bergen (Meuse). Values are measured versus V-PDB.21. Growth is plotted from left to right

between -14 to $-7 \%$, with some extreme excursions to more enriched values.

Both $\delta^{18} 0$ and $\delta^{13} \mathrm{C}$ profiles from the Meuse specimen show very different value ranges compared to those from the Rhine. The $\delta^{18} 0$ values fluctuate between -5.5 and $-7.5 \%$ and the $\delta^{13} \mathrm{C}$ values between -14 to $-11 \%$. For all specimens the range of seasonal variation is about $2 \%$.

The $\delta^{18} 0$ profiles in Fig. 2 show strong seasonal variation. The overall pattern is a signal with sharp peaks and relative broad minima. The sharp peaks represent periods of limited or even interrupted growth (winter), the broad minima favorable conditions (summer). The growth stop below certain temperatures has been reported before (Dettman, 1999; Ricken et al, 2003); for the Unionidae temperatures below $10-12^{\circ} \mathrm{C}$ cause a growth stop. (Dettman,1999). This means that predominantly spring and summer isotopic values are recorded in their shells and winter information is limited to non-existant.

The average $\delta^{18} 0$ values including the standard deviation from this average have been plotted in Fig. 3. The Rhine averages are $-9.39,-9.09$ and $-9.09 \%$ with standard deviation values of $0.94,0.91$ and 0.67 . The average $\delta^{18} 0$ value for Meuse specimen is $-6.5 \%$ with a standard deviation of 0.51 . 0verlap in values between Rhine and Meuse specimens is negligible.

The $\delta^{13} \mathrm{C}$ profiles of the four molluscs share similar features. As seen in Fig. 2, the carbon isotope record of all specimens shows a decrease in $\delta^{13} \mathrm{C}$ over their life span. The overall range for $\delta^{13} \mathrm{C}$ of the shells from the Rhine is -7 to $-14 \%$ and between -10 and $-14 \%$ for the specimen from the Meuse. The decrease is in the order of 1 to $2 \%$ for average $\delta^{13} \mathrm{C}$ values. Another very evident characteristic is the correlation between the $\delta^{13} \mathrm{C}$ and $\delta^{18} 0$ record. There is a shift from a negative correlation in the juvenile stage of the molluscs to a positive one when the organism becomes mature. This happens after the first 2 to 5 years of its life (Gittenberger et al., 1998).

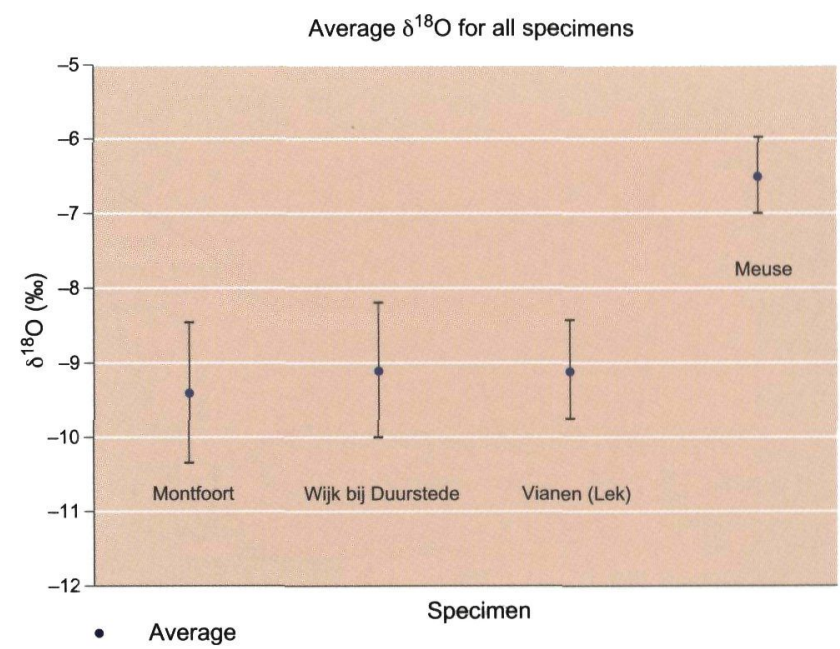

Fig. 3. The average $\delta^{18} 0$ values for the four unionid specimens. 


\section{Discussion}

The direction of summer/winter variation in the $\delta^{18} 0$ profiles (Rhine and Meuse specimens) is similar in all four specimens e.g. winter maxima and summer minima. This is contrary to what was to be expected from the $\delta^{18} 0_{\mathrm{w}}$ profiles of both rivers, which are not in phase. However, the $\delta^{18} 0_{w}$ is not the only factor controlling the oxygen isotopic composition of the carbonate. Another significant control can be the temperature, affecting the isotopic fractionation into the biogenic carbonate to such a degree that the river signal can be obscured. This temperature dependance of $\delta^{18} 0$ fractionation has been observed in other biogenic carbonate tests such as foraminifera and marine molluscs (Epstein et al., 1953; Grossman \& Ku, 1986; Fastovsky et al., 1993), freshwater molluscs (Fritz \& Poplawski 1974; Dettman et al., 1999) and corals (McConnaughey, 1997).
The temperature dependance of $\delta^{18} 0$ as described by Grossman $\& \mathrm{Ku}(1986)$ is particularly suitable for aragonitic bivalves. Their equation has been slightly modified by Dettman et al. (1999) in case freshwater species are used. They found that the relationship estimated by Grossman \& Ku (1986) very closely approximates the $\delta^{18} 0$ composition of the shell. However, when $\delta^{18} 0_{\text {water }}$ drops below $-10 \%$ a systematic error is introduced. Using the data of Grossman and $\mathrm{Ku}$ (1986) Dettman et al. (1999) calculated the direct relationship between the fractionation factor a and temperature. Although the $\delta_{\mathrm{w}}$ values of both rivers are mostly above $-10 \%$, the equation by Dettman et al. (1999) has been used in this paper to determine the role of temperature in the $\delta^{18} 0$ profile (Fig. 4).

In figure 4 the predicted aragonitic $\delta^{18} 0$ composition (open diamonds) and the measured $\delta^{18} 0$ of mollusc shells from both Meuse and Rhine (solid square) have been plotted. The measured
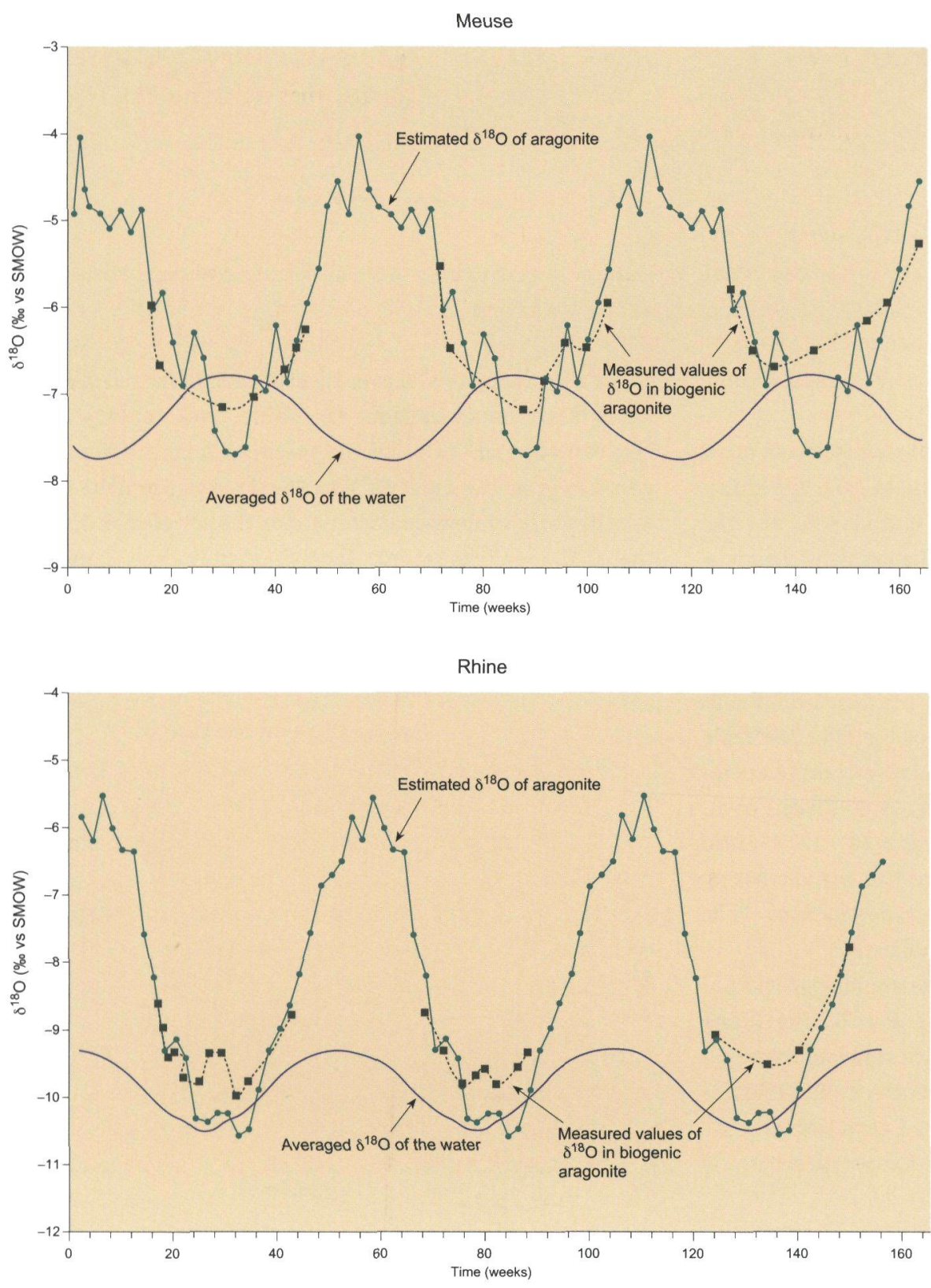

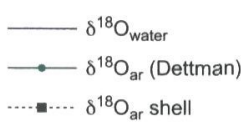

Fig. 4. The effect of temperature on aragonite isotopic composition. The $\delta_{w}$ line is the $\delta^{18} 0$ profile of the water as measured by Mook et al. (1999), from which the same average annual variation is used for every year. The $\delta^{18} 0$ ar profile is the predicted aragonitic $\delta^{18} 0$ composition calculated by using equation 2. The temperature data from one year of measurements near Eijsden for the Meuse, and Lobith for the Rhine, is used (RIZA, waterbase) for all three years. The plotted $\delta^{18} 0$ for shells are the data from Unio crassus batavus from the Meuse and the recent specimen from the Lek for the Rhine. Measured $\delta^{18} 0$ values for the biogenic carbonate are stretched horizontally to fit in the graph. 
values are fitted over the estimated $\delta^{18} \mathrm{O}_{\mathrm{ar}}$ profile by corresponding the minima of the measured profile to the minima of the predicted one, based on temperature and isotopic ratios of the river water. The rest of the data points are fitted on the predicted plot by placing the first data point of a new year in the week when the water reached a temperature above $12^{\circ} \mathrm{C}$ (the temperature where unionids continue growth; Dettman et al., 1999) and the last data point in the last week before water temperature dropped below this limit.

It is clear from this figure that temperature has a large effect on the seasonal profile of the molluscan shell material. The effect of temperature on the ${ }^{18} 0$ distribution between water and carbonate is most significant in the winter periods. The summer temperatures of the river water are close to the the temperature where there is no fractionation $\left(20.6^{\circ} \mathrm{C}\right.$ according to Grossman and $\mathrm{Ku}, 1986$ ) but during winter, when temperature drops to only a few degrees Celcius, the $\delta^{18} 0$ value of the aragonite becomes 3.5\% more enriched than the river water. It is because of the growth cessation that the calculated average $\delta^{18} 0$ value of the total profiles of all shells still resembles the river water $\delta^{18} 0$ value. Although the summer temperatures for both rivers seem to be close to the nonfractionation temperature, the measured $\delta^{18} 0$ values for shell material precipitated during summer are still slightly more enriched than would be expected. There are complicating factors: the temperatures measured are surface water temperatures, while the unionids live partially buried in the sediments where temperatures are likely to be colder during summer and warmer during winter. However, this is beyond the scope of this paper and needs additional monitoring and calibration.

Fig. 4 just hints at the mechanism that influences the average isotopic composition of unionid shells. This appears to be threefold. Firstly the temperature effect causes the winter values for shell carbonate to be more enriched in ${ }^{18} 0$ compared to the water values, whereas summer values are approximately equal to river water composition. This results in a more positive value for mean $\delta^{18} 0$. Secondly, growth stops when temperatures drop below $12^{\circ} \mathrm{C}$. This causes the average $\delta^{18} 0$ composition to be less effected by the winter temperatures and thus makes it more negative. Finally, the last factor that influences the average isotopic composition is growth rate. This is maximal during summer, thus it is during this period that het majority of the carbonate is precipitated. This results in a large fraction of shell material with low ${ }^{18} 0 /{ }^{16} 0$ ratio's and just a few data point with more positive values. This effect shifts the mean isotopic composition in the negative direction. When comparing the average $\delta^{18} 0$ values of the three Rhine specimens they do not differ significantly from each other despite the fact that they vary considerably in age. This indicates that they experienced approximately the same temperatures, had the same temperature limit for shell growth and precipitated equal portions of shell material in summer relative to colder periods.
However, there is a slightly more negative $\delta^{18} 0$ for the oldest shell compared to the other two. When studying the isotopic profile of this shell, it becomes clear that the slightly lower average for $\delta^{18} 0$ is caused by lower spring values. This specimen was found in crevasse sediments (Berendsen, pers. comm.), a part of the river system that only becomes flooded occasionally. This could imply that it only grew when it was surrounded by water and thus when it was spring and summer, during which the Rhine receives the melt water from the Swiss alps. When the majority of the shell is precipitated during the spring and summer season, the average $\delta^{18} 0$ value of the shell will be lower than when the shell also (partially) grew during winter, when high $\delta^{18} 0$ values are recorded. This is the most probable explanation for this phenomenon. Another factor that could have caused an altered value for $\delta^{18} 0$ relative to the more recent species is a different river water composition with respect to the stable isotope. Mixing with river water from the Meuse river system is not what is causing the difference here, because this would give an average $\delta^{18} 0$ value that would be more positive than that of the other specimens. This is not the case for the unionid from Montfoort.

\section{$\delta^{13} \mathrm{C}$ in unionid shells}

The values for $\delta^{13} \mathrm{C}$ of dissolved inorganic carbon in the Rhine and Meuse show a seasonal variation, as can be seen in Fig. 2 . These rivers are most enriched in $13 \mathrm{C}$ during the summer (july-august), $\delta^{13} \mathrm{C}$ ranges between -11 and $-9 \%$ for the Rhine and -12 and $-10 \%$ for the Meuse (Mook., 1999) during that period.

Over the year, the $\delta^{13} \mathrm{C}$ values of shells from the Rhine range from -7 to $-14 \%$ (Montfoort), -5 to $-15 \%$ (Wijk bij Duurstede) and -7 to $-13 \%$ (Vianen (Lek)). When compared to the $\delta^{13} \mathrm{C}$ of the DIC in this river it becomes clear that this isotope is not incorporated in equilibrium with the ambient water composition. In general the profiles for the biogenic carbon and $\mathrm{DIC}_{\text {river }}$ are in phase during the juvenile years, but minimum and maximum $\delta^{13} \mathrm{C}$ exceed the $\delta^{13}$ DIC. A possible factor for disequilibrium between $\delta^{13} C_{\text {DIC }}$ and $\delta^{13} C_{a r}$ is kinetic frationation. When this is the only factor controlling stable oxygen and carbon isotope composition, a close relationship would exist between $\delta^{13} \mathrm{C}$ and $\delta^{18} 0$. The stable isotope data for all four shells show no significant correlation, thus most likely the non-equilibrium fractionation observed is related to metabolic control (Dettman et al., 1999). The biogenic carbonate for all three Rhine molluscs is enriched in ${ }^{13} \mathrm{C}$ relative to the water. This might be due to a local increase in ${ }^{13} \mathrm{C}$ during the elevated uptake of ${ }^{12} \mathrm{C}$ in the summer for photosynthesis in other organisms. The depletion of the winter values for $\delta^{13} \mathrm{C}$ are probably caused by the metabolic effect of the molluscs, which dilutes the ambient water composition with light $\mathrm{CO}_{2}$. The mollusc discriminates against the ${ }^{13} \mathrm{C}$ isotope during metabolism and thus when there is high metabolic activity the 
extra pallial fluid (EPF) will receive components with a relative less amount of ${ }^{13} \mathrm{C}$. This could very well also be the cause of the overall decrease in $13 \mathrm{C}$ during the life of the animal. As reported by Klein et al. (1996), a high metabolic rate results in an increased intracellular: intercellular ratio. Because intracellular transport to the extrapallial fluid comes with a discrimination against ${ }^{13} \mathrm{C}$, a higher metabolic rate leads to a decreased $\delta^{13} \mathrm{C}$. The shift from negative to positive correlation between $\delta^{18} 0$ and $\delta^{13} \mathrm{C}$ after a several years is recognized in all four specimens. Because winter values for $\delta^{13} \mathrm{C}$ approximately remain constant, the reason for this shift originates in the behavior of the animal during spring and summer. The age at which the Unio crassus nanus becomes sexually active lies between 3 and 5 years (Gittenberger et al., 1998). When breeding it is very likely that the mollusc requires a higher metabolic activity. Due to this elevated metabolic rate the extrapallial fluid becomes depleted and possibly this extensive reduction in ${ }^{13} \mathrm{C}$ will exceed the local enrichment phenomenon mentioned earlier in this study. The Meuse specimen shows a somewhat different pattern. Similar to the Rhine specimen the summer $\delta^{13} \mathrm{C}$ in the biogenic carbonate becomes depleted in ${ }^{13} \mathrm{C}$, but simultaneously, winter values become enriched and the overall decrease in $\delta^{13} \mathrm{C}$ is less evident in this profile. Possibly a gradual increase in $\delta^{13} \mathrm{C}$ of the Meuse water is the reason why the extensive decrease in $\delta^{13} \mathrm{C}$ of the mollusc carbonate failed to occur in its mature stage. This would also explain why the winter values for $\delta^{13} \mathrm{C}$ suddenly start to increase. Although the $\delta^{13} \mathrm{C}$ profile depends on various factors and therefore represents a very complex mechanism, an overall pattern can be distinguished. A decrease in $\delta^{13} \mathrm{C}$ relative to the ambient water composition and a shift in correlation with $\delta^{18} 0$, possibly when the animal starts reproduction, can be recognized in all four specimens.

\section{Conclusions}

Our study on molluscs from the rivers Rhine and Meuse indicates that the average $\delta^{18} 0$ values obtained from molluscan carbonate reveals the average stable oxygen isotopic composition of the river water in which the animal lived. Although the oxygen isotopic ratio of the water is altered during incorporation into the aragonite as a result of temperature fractionation, the average values are clearly different between the Rhine and Meuse specimens. The $\delta^{18} 0$ of the water is the major control on the ${ }^{18} 0$ fractionation in these shells, but the temperature effect appeared powerful enough to obscure the characteristic isotopic signal of the Meuse river water. Addional to this temperature effect, the average isotopic composition of the shell is affected by growth stop during the winter period and the differing growth rates in between seasons. These three factors seem to balance each other for these specimens.

\section{Acknowledgements}

The authors are indebted to Bram bij de Vaate (RIZA), Henk Berendsen (UU) and Wim Kuijper (RUL) for providing unionid specimens. The comments of Tom Meijer and an anonymous reviewer greatly improved the text.

\section{References}

Berendsen, H.J.A. \& Stouthamer, E., 2001. Paleogeographic development of the Rhine-Meuse delta, the Netherlands. Assen: Koninklijke Van Gorcum: $268 \mathrm{pp}$.

Dettman, D.L., 1999. Controls on stable isotope composition of seasonal growth bands in aragonitic fresh-water bivalves (unionidea), Geochimica et Cosmochimica Acta 63 (7/8): 1049-1057.

Epstein, S., Buchsbaum, R., Lowenstam, H.A. \& Urey, H.C., 1953. Revised carbonate-water isotopic temperature scale. The Geological Society of America Bulletin 64: 1315-1326.

Fastovsky, D.E., Arthur, M.E., Strater, N.H. \& Foss, A., 1993. Freshwater bivalves (Unionidae), disequilibrium isotopic fractionation, and temperatures, Palaios 8: 602-608.

Fritz, P. \& Poplawski, S., 1974. ${ }^{18} 0$ and ${ }^{13} \mathrm{C}$ in the shells of freshwater molluscs and their environments, Earth and Planetary Science Letters 24: 91-98.

Gittenberger, E., Janssen, A.W., Kuijper, W.J., Kuiper, J.G.J., Meijer, T., Van der Velde, G. \& De Vries, J.N., 1998. De Nederlandse Zoetwatermollusken. Nationaal Natuurhistorisch Museum Naturalis, KNNV Uitgeverij (Nederland): $288 \mathrm{pp}$.

Grossman, E.L. \& Ku, T., 1986. 0xygen and carbon isotope fractionation in biogenic aragonite: temperature effects, Chemical Geology (Isotope Geoscience section) 59: 59-74

Klein, C. \& Hurlbut, C.S., 1993. Manual of mineralogy, 21st edition, University of New Mexico: $411 \mathrm{pp}$.

Klein, R.T., Lohmann, K.C. \& Thayer, C.W., 1996. Sr/Ca and ${ }^{13} \mathrm{C} /{ }^{12} \mathrm{C}$ ratios in skeletal calcite of Mytilus trossulus: Covariation with metabolic rate, salinity and carbon Isotopic composition of seawater, Geochimica et Cosmochimica Acta 60 (21): 4207-4221.

McConnaughey, T.A., 1997. Carbon isotopes in biological carbonates: Respiration and photosynthesis, Geochimica et Cosmochimica Acta, 61 (3): 611-622.

Mook, W.G., 1999. Environmental isotopes in the hydrological cycle: Principles and Applications, Volume I: Introduction, theory, methods and reviews, Center for Isotope Research, Groningen.

Rosenthal, Y. \& Katz, A., 1989. The applicability of trace elements in freshwater shells for paleogeochemical studies, Chemical Geology: 78: 65-76.

Ricken, W., Steuber, T., Freitag, H., Hirschfeld, M. \& Niedenzu, B., 2003. Recent and historical dicharge of a large European river system-oxygen isotopic composition of river water and skeletal aragonite of Unionidae in the Rhine. Palaeogeography, Palaeoclimatology, Palaoeoecology 193: 73-86. 